\title{
Extending Postharvest Storage Life of Non-astringent Persimmon cv. Fuyu by 1-MCP Treatments
}

\author{
Naveen Kumar ${ }^{*}$ and K. S. Thakur
}

Dept. of Food Science and Technology, Dr. Y.S. Parmar University of Horticulture and Forestry, Nauni, Solan, H.P. (173 230), India

\section{Corresponding Author}

Naveen Kumar

e-mail: naveen82381@gmail.com

\author{
Article History \\ Article ID: 3 C0615 \\ Received in $26^{\text {th }}$ October, 2017 \\ Received in revised form $18^{\text {th }}$ December, 2017 \\ Accepted in final form $22^{\text {nd }}$ January, 2018
}

\begin{abstract}
Persimmon is the species Diospyros kaki, a tree belonging to the family Ebenaceae and native to the Far East. Originally cultivated in China and Japan, it is also known as Chinese date plum. A research was carried out to understand the potential of the commercial use of 1-MCP (1 methylcyclopropene) to extend the shelf life of the non-astringent persimmon cultivar cv. Fuyu. Persimmon (Diospyros kaki L.) fruit were harvested at the commercial maturity (yellowish orange colour) and then treated with 1-methylcyclopropene (1-MCP) at three different doses $(250 \mathrm{ppb}, 500 \mathrm{ppb}$ and $750 \mathrm{ppb})$ for $24 \mathrm{hrs}$ at $20^{\circ} \mathrm{C}$ and kept at ambient air temperature $\left(20^{\circ} \mathrm{C}\right)$ for shelf life evaluation. The result showed that the non 1-MCP treated fruit softened within 15 days after harvest, resulting in unacceptable quality as compare to all 1-MCP treated fruits. The 1-MCP treatments at more than $500 \mathrm{ppb}$ inhibited fruit softening for 30 days after harvest in association with suppression of respiration at room temperature and thus helps in retaining the fruit firmness. Treatment with 250 ppb 1-MCP had a limited inhibitory effect on softening. Change in soluble solid content, acid and peel colour occurred during storage, but all these processes were significantly delayed by 1-MCP treatment. These results indicated that 1-MCP is an effective tool for quality improvement and extension of shelf life in persimmon and fruit might be harvested in yellowish orange stage of ripening, at which the most desirable organoleptic attributes had been developed on tree.
\end{abstract}

Keywords: Persimmon, non-astringent, storage life, 1-MCP

\section{Introduction}

Persimmon (Diospyros kaki L.) belongs to family Ebenaceae and is a popular commercial fruit in China, Korea and Japan. The genus Diospyros has approximately 200 species including $D$. virginiana and $D$. lotus which are used as rootstocks for raising commercial persimmon varieties (Garcia-Carbonell et al., 2002). It was originally cultivated in China and Japan, and is also known as the Chinese Date Palm and is the national fruit in Japan. Persimmon is cultivated throughout the warmer parts of the world e.g. Asian and other Mediterranean countries. In India persimmon was introduced in 1921 by Captain A.N. Lee in Kullu valley and has been found to grow successfully at elevations ranging from 500 to $900 \mathrm{~m}$ above mean sea level. In Himachal Pradesh, it is being cultivated only on a limited scale in Kullu, Mandi, Solan, Shimla and Sirmor districts, though due to its high price and nutritional importance its cultivation is picking up (Anonymous, 2012).

Non astringent persimmon is an excellent fruit crop with excellent texture and taste. The most limiting factor for distribution and storage of this cultivar is rapid softening during postharvest period. 1 methylcyclopropene (1-MCP), is a potent inhibitor of ethylene action, with potential to delay ripening and senescence and to reduce physiological disorders, thereby extending postharvest life of various horticultural crops (Blankenship and Dole, 2003), however other techniques like modified atmosphere packaging and control atmosphere packaging are also found beneficial for storage of several fruits (Dorria et al., 2011). The relationship between ethylene and $\mathrm{Cl}$ in persimmon fruit has been shown previously by some authors (Burmeister et al., 1997, Woolf et al., 1997). Chill injured fruit produced more ethylene than non-chilled fruit on removal from storage 1-MCP reduced $\mathrm{Cl}$ symptoms of cold stored 'RojoBrillante' persimmon (Besada et al., 2008, Perez-Munuera, 2009), however the effects of 1-MCP on 'Karaj' persimmon have not been elucidated.

\section{Materials and Methods}

\subsection{Plant material}

Non astringent persimmons cv. 'Fuyu' were harvested at the yellow-orange maturity stage from a Regional horticulture research station Seobagh, Kullu, Himachal pradesh, India, 24 September, 2016. Fruit were transported to the laboratory in UHF, Nauni, Solan, Himachal Pradesh for the application the following MCP treatments. After the application of treatments the fruits will be stored under ambient conditions and fruit 
quality will be evaluated periodically at 10 days interval for initial firmness, total soluble solids, total sugars, ascorbic acid and respiration rate.

\subsection{1-MCP treatment}

Persimmon fruits were treated triplicate, using $2 \mathrm{~kg}$ fruits per replicate, with 1-MCP at different concentrations. The commercial formulation of 1-methylcyclopropene (1-MCP) containing 3.3\% of the active ingredient was procured from M/S Rohm and Hass Ltd. and applied (250 ppb, 500 ppb and $750 \mathrm{ppb}$ ) as a fumigation treatment by placing the persimmon fruits in a closed airtight tent for 24 hrs after dissolving the commercial formulation of 1-MCP in demineralised water and placing the solution inside the tent along with fruits. After the treatment, fruits were stored at ambient room temperature in brown paper bags and evaluated for the period of 30 days at 10 days interval for initial firmness, total soluble solids, total sugars, titrable acidity, ascorbic acid and respiration rate.

\subsection{Physico-chemical analysis}

Fruit firmness was measured with a portable Effigi penetrometer (FT-327) which recorded the pressure required to force a plunger of 8 millimeters $(\mathrm{mm})$ diameter into the flesh of the fruit samples. Soluble solid content were measured with hand refractrometer. Titrable acidity was measured by titration method (0.1N NaOH) (Hortwitz, 1980). Total sugar was measured by Lane and Eynon, (1923) method. Ascorbic acid content was determined as per standard AOAC method (Ranganna, 1986) using 2,6- dichlorophenol indophenol dye. The rate of respiration was measured as carbon-dioxide evolved per unit weight of fruit per unit time. Known weight of fruit was enclosed in an airtight container of known volume for a known time and the carbon dioxide evolved due to respiration was measured with the help of Gas data analyser (GFMseries 301/2/3,Gas Data Ltd.Coventry UK)and was expressed as $\mathrm{ml} \mathrm{CO}_{2} \mathrm{~kg} \mathrm{hr}^{-1}$.

\subsection{Statistical analysis}

Data were subjected to analysis of variance (ANOVA) and analysed by Completely Randomized Design (CRD) with three replications (Mahony, 1985).

\section{Results and Discussion}

A significant decrease in flesh firmness was observed as the fruits ripened and softened with longer storage duration (Figure 1). Fruit firmness is regarded as a decisive factor determining the degree of fruit ripening and shelf life. In this study, the maximum fruit firmness was recorded on 0 day and minimum fruit firmness was recorded on 30 day time interval. With respect to $250 \mathrm{ppb}$ treatment, it was $9.50 \mathrm{~kg}$ at 0 day and it decreased to $1.50 \mathrm{~kg}$ after 30 day and in case of $500 \mathrm{ppb}$, it was $9.75 \mathrm{~kg}$ at 0 day and 1.65 at 30 day, similar trend was observed with $700 \mathrm{ppb}$ treatment with maximum firmness $9.70 \mathrm{~kg}$ and minimum fruit firmness $1.90 \mathrm{~kg}$. The shelf life was 2 times longer for fruits treated with 1-MCP than untreated

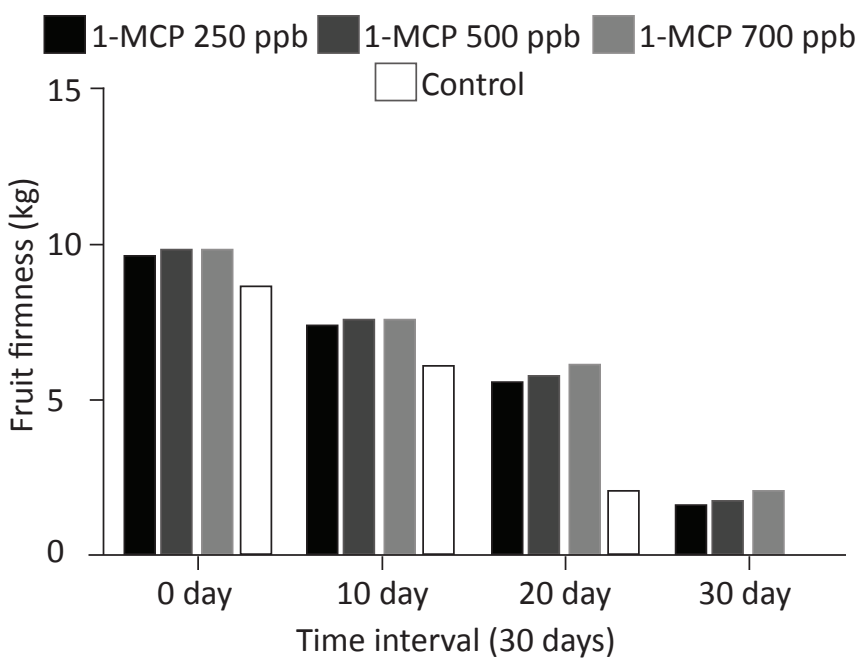

Figure 1: Effect of 1-MCP on fruit firmness in persimmon during storing at ambient temperature

fruits. These observations indicate that 1-MCP treatments extend the shelf life of Fuyu persimmon by atleast 2 times over that of non-treated control fruit.

The total soluble solid content (TSS) of fruit showed the increasing trend however it starts decreasing after 25 days (Figure 2). With respect to $250 \mathrm{ppb}$ treatment it started from $13.50^{\circ} \mathrm{B}$ at 0 day and reached at $18.50^{\circ} \mathrm{B}$ at 20 day, after 25 days it decreased to $16.25^{\circ} \mathrm{B}$. Same trend was recorded with $500 \mathrm{ppb}$ and $750 \mathrm{ppb}$ treatment. Whereas in control fruit TSS reached to $18.20^{\circ} \mathrm{B}$ at $10^{\text {th }}$ day after that it decreased to 16 ${ }^{\circ} \mathrm{B}$ at $20^{\text {th }}$ day and start spoiling.

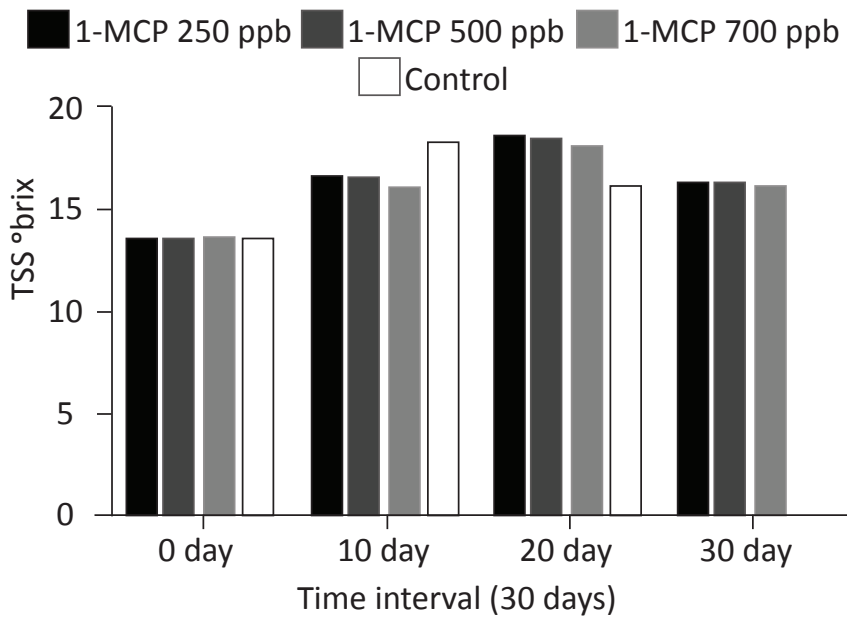

Figure 2: Effect of 1-MCP on TSS (oBrix) in persimmon during storing at ambient temperature

An increasing trend in total sugar content was observed upto the 25 days of storage under all the 1 - M C P treatments following a decline during the next 5 days during ambient storage (Figure 3). With respect to 1-MCP 750 ppb concentration, it showed the less increase in total sugar content and extends the shelf life of persimmon as compare to other 1-MCP treatments 


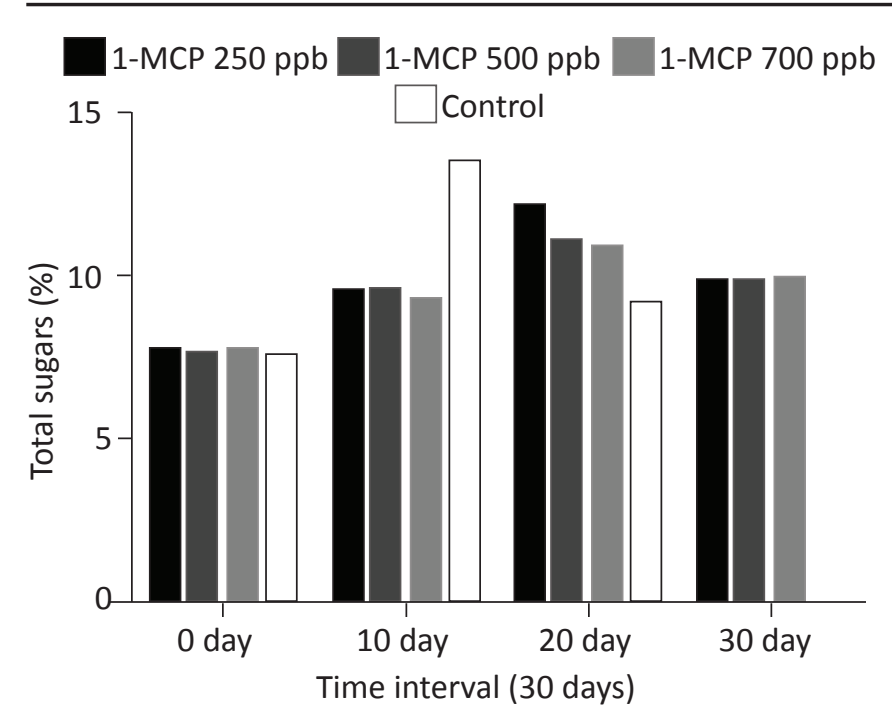

Figure 3: Effect of 1-MCP on total sugars (\%) in persimmon during storing at ambient temperature

while control sample spoiled within 20 days of storage.

Ascorbic acid content was gradually decreased with advancement of time period (Figure 4). The mean ascorbic acid level was observed to be highest on the $0^{\text {th }} \mathrm{d}$ a y w it h values

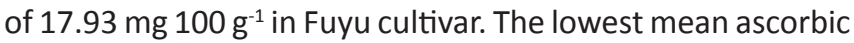
acid content was recorded on the $30^{\text {th }}$ sampling date with mean

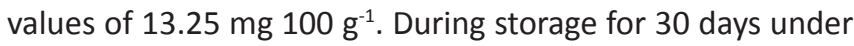
ambient conditions the ascorbic acid content exhibits a decline in all the 1-MCP treatments and it decreased from 17.98 to

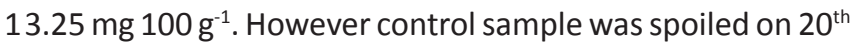

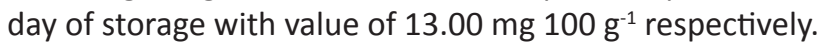

1-MCP 250 ppb $\quad 1$ 1-MCP 500 ppb $\quad 1$ 1-MCP 700 ppb

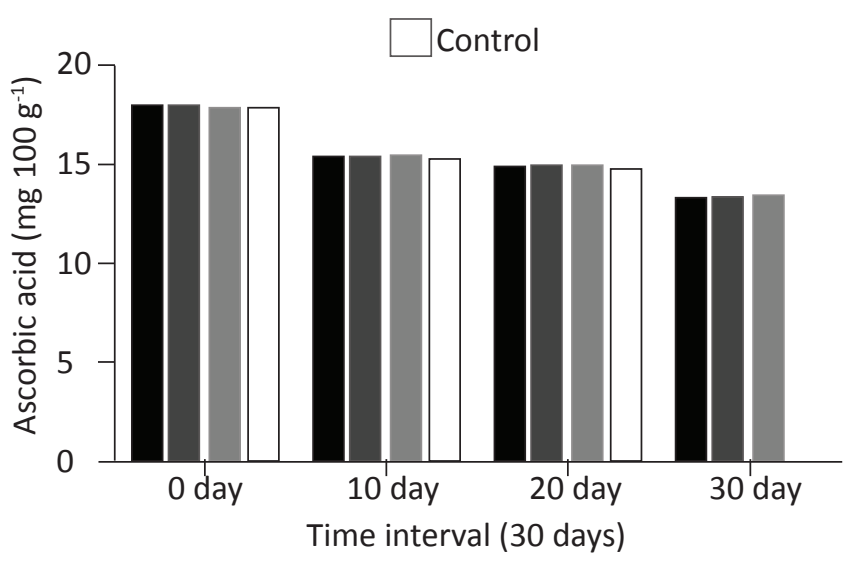

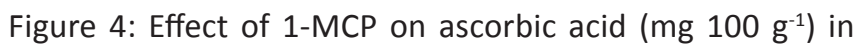
persimmon during storing at ambient temperature

There was a gradual increase in the respiration rate upto 25 days in ambient storage and there after a decrease was recorded during the next five days (Figure 5). However, this pattern was relatively faster in control fruits reaching peak values for respiration after 15 days and there after a gradual decline was observed during the remaining days. The lowest mean respiration rate $\left(10.42 \mathrm{mlCO}_{2} \mathrm{~kg} \mathrm{hr}^{-1}\right)$ was observed

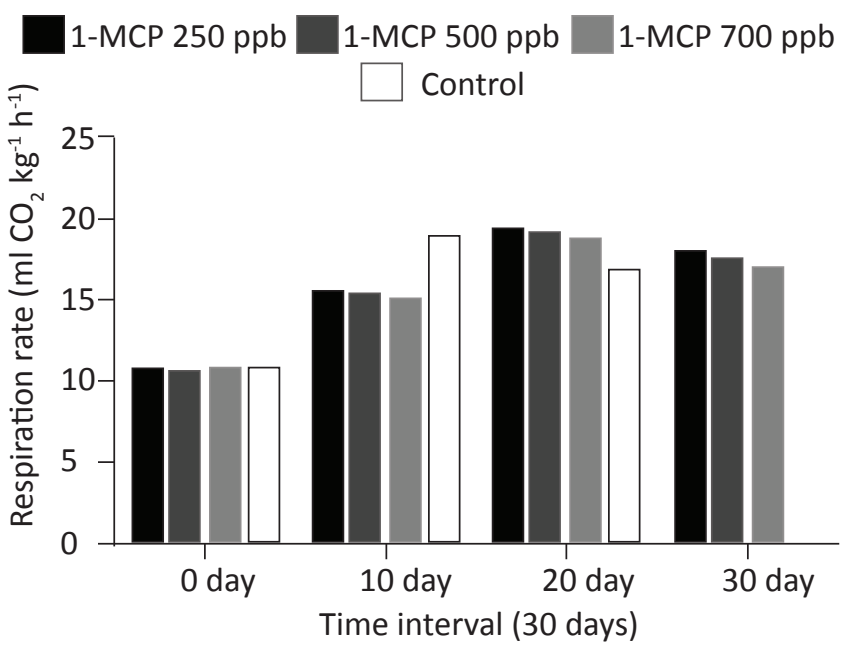

Figure 5: Effect of 1-MCP on respiration rate $\left(\mathrm{ml} \mathrm{CO}_{2} \mathrm{~kg}^{-1} \mathrm{~h}^{-1}\right)$ in persimmon during storing at ambient temperature

on $0^{\text {th }}$ day whereas the control fruits exhibited the highest respiration rate $\left(\mathrm{mLCO}_{2} \mathrm{~kg} \mathrm{hr}^{-1}\right)$ which was significantly more than that recorded in all other treatments.

The study showed that 1-MCP delayed fruit softening, reduced the loss of soluble solid content and rate of respiration in Fuyu persimmon after 30 days of storage at ambient temperature. These results support the observation of Kim and Lee (2005) storing other cultivars in cold and room conditions. The higher TSS and sugars content in control fruits during the initial sampling dates might be due to faster ripening changes resulting in breakdown of complex carbohydrates into simple sugars at a faster rate thereby increasing these constituents to the maximum extent and also due to the higher transpiration losses (Suni et al., 2000). Softening of fruits is caused either by breakdown of insoluble proto pectin into soluble pectin or by hydrolysis of starch (Mattoo et al., 1975). The maintenance of higher firmness as a result of 1-MCP treatment may be due to its ability to prevent PLW during storage and to inhibit ethylene production (Dong et al., 2002). It was observed that the ascorbic acid content of fruit exhibited a gradual decline with increase in storage duration under all the treatments with the fastest decline being recorded in control fruits which consequently exhibited significantly lowest ascorbic acid contents. The loss in ascorbic acid content during storage might be due to its degradation during metabolic processes or through enzymatic oxidation of L-ascorbic acid to dehydro ascorbic acid (Mapson, 1970), as well as utilization by developing microorganisms (Tandon and Tandon, 1974; Tanejaet al., 1983). Lower rate of respiration in fruits treated with 1-MCP in comparison to control sample could be due to its ability to prevent ethylene action, thus having a direct effect on reducing the respiration rate of fruits. Inhibition of ethylene action by 1-MCP during fruit ripening has also been reported by various workers in apple (Fan and Mattheis, 1999; Watkins et al. 2000), peach (Chang et al., 2003; Grimaet al., 2005), plum (Khan and Singh, 2008) and mango (Wang et al., 2008). 


\section{Conclusion}

1-MCP treatment markedly extend the shelf life of non astringent persimmon cultivar Fuyu fruit and hence helps keeping quality for up to 30 days at ambient temperature as compare to control that maintained the quality for 20 days. Therefore, we found 1-MCP treatment at the concentration of 750 ppb was the best for the shelf life extension of persimmon fruit.

\section{References}

Anonymous, 2012. Horticulture development at a glance (hpagrisnet.gov.in).

Besada, C., Arnal, L., Salvado, A., 2008. Improving storability of persimmon cv. Rojo Brillante by combined use of preharvest and postharvest treatments. Postharvest Biology and Technology 50, 169-175.

Blankenship, S.M., Dole, J.M., 2003. 1-Methylcyclopropene: A review. Postharvest Biology and Technology 28, 1-25.

Burmeister, D.M., Ball, S., Green, S., Woolf, A.B., 1997. Interaction of hot water treatments and controlled atmosphere storage on quality of 'Fuyu' persimmon. Postharvest Biology and Technology 12, 71-81.

Dong, L., Lurie, S., Zhou, H.W., 2002. Effect of 1-methylcyclopropene on ripening of 'Canino' apricots and 'Royal Zee' plums. Postharvest Biology and Technology 24, 135-145.

Dorria, M., Ahmed, A., Yousef, R.M., Sarrwy, S.M.A., 2011. Modified Atmosphere Packaging for Maintaining Quality and Shelf Life Extension of Persimmon Fruits. Asian Journal of Agricultural Sciences 3(4), 308-316.

Garcia-Carbonell, S., Yague, B., Bleiholder, H., Hack, H., Meier, U., Agusti, M., 2002. Phenological growth stages of the persimmon tree (Dispyros kaki). Annal of Applied Biology 141, 73-76.

Hortwitz, W., 1980. Official Methods of Analysis, $13^{\text {th }}$ ed. Association of Annual Chemistry, Washington, D.C.

Kim, Y., Lee, J.M., 2005. Extension of storage and shelf life of sweet persimmon with 1-MCP. Acta Horticulture 658, 165-174.
Lane, J.H., Eynon, L., 1923. Determination of reducing sugar by Fehling's solutions with methylene blue as indicator. Journal of the Society of Chemical Industry 42, 32.

Mahony, M.O., 1985. Sensory Evaluation of Food: Statistical Methods and Procedures. Marcel Dekker. Inc. Newyork.

Mapson, L.W., 1970. Vitamins in fruits. In: Hulme, A.C. (Ed.), The Biochemistry of Fruits and Their Products, vol. 1. Academic Press, London, 369-383.

Mattoo. A.K., Murata, T., Pantastico, E.B., Chachin, K., Ogata, K., Phan, C.T., 1975. Chemical changes during ripening and senescence. In: Pantastico, E.B. (Ed.), Post-harvest physiology, handling and utilization of tropical and sub-tropical fruits and vegetables. The AVI Pub Co Inc, Westport, Connecticut, 103-127.

Perez-Munuera, I., Hernando, I., Larrea, V., Beasada, C., Arnal, L., Salvador, A., 2009. Microstructural study of chilling injury alleviation by 1-methylcyclopropene in persimmon. Hort Science 44, 1-4.

Ranganna, S., 1986. Handbook of Analysis and Quality Control of Fruit and Vegetable Products. 2nd ed. Tata McGraw Hill Publication Company, New Delhi.

Suni, M., Nyman, M., Eriksson, N.A., Bjork, L., Bjork, I.. 2000. Carbohydrate composition and content of organic acids in fresh and stored apples. Journal of the Science of Food and Agriculture 80(10), 1538-1544.

Tandon, M.P., Tandon, R.N., 1974. Post infection changes in ascorbic acid contents of aonla fruits caused by Aspergillus niger. Current Science 43(7), 218-219.

Taneja, S., Parmar, M.S.S., Williamson, S., Jain, D., 1983. Changes in ascorbic acid contents of aonla fruit (Emblica officinalis Gaertn.) after fungal infection. Science Culture 48, 225-226.

Woolf, A.B., Ball, S., Spooner, K.J., Lay-Yee, M., Ferguson, I.B., Watkins. C.B., Gunson. A., Forbes, S.K., 1997. Reduction of chilling injury in the sweet persimmon 'Fuyu' during storage by dry air heat treatments. Postharvest Biology and Technology 11, 155-164. 